\title{
APLICAÇÕES DA FABRICAÇÃO DIGITAL EM ARQUITETURA, DESIGN E CONSTRUÇÃO: PROCESSOS DE APROPRIAÇÃO TECNOLÓGICA E ADEQUAÇÃO SOCIOTÉCNICA EM EXPERIMENTOS NA AMÉRICA DO
} SUL

\author{
APPLICATIONS OF DIGITAL FABRICATION IN ARCHITECTURE, DESIGN AND \\ CONSTRUCTION: PROCESSES OF TECHNOLOGICAL APPROPRIATION AND SOCIO- \\ TECHNICAL ADAPTATION IN EXPERIMENTS IN SOUTH AMERICA
}

Rodrigo Scheeren ${ }^{1}$, David M. Sperling ${ }^{1}$

\section{RESUMO:}

Conforme o avanço e a disseminação das tecnologias de fabricação digital nos campos da arquitetura, design e construção, torna-se oportuno sistematizar os laboratórios que as implementam e compreender como estão ocorrendo as suas dinâmicas de uso no contexto da América do Sul. Como parte de um projeto de pesquisa em andamento, o objetivo do artigo é elencar alguns dos experimentos projetuais identificados durante a investigação e apresentá-los por meio de categorias baseadas em similaridades de propostas temáticas e conceitos, além de suas relações com as tecnologias. Os métodos utilizados abrangem a revisão da literatura e revisão sistemática de publicações, mapeamento de informações, questionários semiestruturados e estudos de caso. Os artefatos selecionados são analisados conforme os temas da apropriação tecnológica, adequação sociotécnica e inovação social, manifestando uma perspectiva local de estratégias de produção frente a demandas e necessidades, a partir do emprego de técnicas e tecnologias digitais. O contexto recente de instalação dos laboratórios de fabricação digital foi se ampliando nas instituições por meio do ensino e da pesquisa, além da consolidação do modelo Fab Lab na região. Os resultados práticos são muito heterogêneos em seus temas, concebidos com prazo de durabilidade curto, ainda limitados em escala e fortemente baseados na articulação formal híbrida entre o analógico e o digital, devido aos materiais disponíveis, tipo de maquinário acessível e da especialização técnica necessária para produzi-los, mas com alguns projetos direcionados à solução de problemas no aspecto social.

PALAVRAS-CHAVE: Fabricação digital; Apropriação tecnológica; Adequação sociotécnica; Inovação social; Design arquitetônico.

\section{ABSTRACT:}

According to the advancement and dissemination of digital fabrication technologies in the fields of architecture, design and construction, it becomes opportune to systematize the laboratories that implement them and understand how their dynamics of use are occurring in the context of South America. As part of an ongoing research project, the objective of the article is to list some of the design experiments identified during the investigation and to present them through categories based on similarities of thematic proposals and concepts, in addition to their relationship with technologies. The methods used include a literature review and systematic review of publications, information mapping, semi-structured questionnaires and case studies. The selected artifacts are analyzed according to the themes of technological appropriation, socio-technical adequacy and social innovation, showing a local perspective of production strategies in the face of demands and needs, based on the use of digital techniques and technologies. The recent context of the implementation of digital fabrication laboratories has been expanding in institutions through teaching and research, in addition to the consolidation of the Fab Lab model in the region. The practical results are very heterogeneous in their themes, conceived with a short term of durability, still limited in scale and strongly based on the formal hybrid articulation between analog and digital, due to the available materials, the type of accessible machinery and the technical specialization necessary for producing them, but with some projects aimed at solving problems in the social aspect. KEYWORDS: Digital fabrication; Technological appropriation; Socio-technical adequacy; Social innovation; Architectural design.

How to cite this article:

SCHEEREN, R.; SPERLING, D. M. Aplicações da fabricação digital em arquitetura, design e construção: processos de apropriação tecnológica e adequação sociotécnica em experimentos na América do Sul. Gestão \& Tecnologia de Projetos. São Carlos, v15, n3, p.18-, 2020. https://doi.org/10.11606/gtp.v15i3.166255
${ }^{1}$ Universidade de São Paulo. Instituto de Arquitetura e Urbanismo - IAU USP

Fonte de Financiamento: Fundação de Amparo à Pesquisa do Estado de São Paulo - FAPESP e Conselho Nacional de Desenvolvimento Científico e Tecnológico - CNPq

Conflito de Interesse: Declara não haver.

Submetido em: 11/02/2020 Aceito em: 08/07/2020 


\section{INTRODUÇÃO}

A disciplina da arquitetura foi expandida em suas práticas e formas de atuação nas últimas décadas devido a uma série de mudanças técnicas e tecnológicas, centradas principalmente na evolução do paradigma digital (PICON, 2010), com avanços ocorrendo no âmbito dos processos computacionais de projeto (MENGES AHLQUIST, 2011) e na esfera da fabricação digital (CANEPARO, 2014). A possibilidade de materializar os conceitos projetados permeia o interesse dos arquitetos por atividades práticas que se constituem desde a aplicação das tecnologias por meio da prototipagem rápida (Sass; Oxman, 2006) até em experimentos materiais utilizando métodos avançados que articulam o estado da arte das tecnologias industriais em processos para a construção (NABONI, PAOLETTI, 2015). Em paralelo, laboratórios de investigação se consolidaram em instituições de ensino (CELANI, 2012), propostas de fabricação pessoal, assim como nos Fab Labs, que indicam um potencial de "revolução" na área (GERSHENFELD, 2005; 2012). Desse modo, a expansão do vocabulário de criação, da análise e da simulação de projetos cada vez mais complexos está sendo materializada por processos de fabricação que investigam a utilização das máquinas de controle numérico computacional, com a finalidade de automatizar o design para a produção.

De acordo com qualquer contexto sociotécnico, os artefatos produzidos devem ser compreendidos de forma vinculada aos seus meios de produção, às relações de trabalho, e aos potenciais de transformação desse mesmo contexto. Em virtude dessas condições, existem posições críticas em relação ao papel das tecnologias e suas condições de efetivação. As alterações no processo de produção da construção pelas tecnologias de fabricação digital decorrem de mudanças fundamentais nas estruturas sociais e de mercado, não como práticas tecnicamente determinadas, mas que evoluem e são estabelecidas por necessidades e desenvolvimentos sociais e culturais (MOE, 2010, p. 164-5). Entre a promoção de princípios de abertura, democratização, empoderamento e compartilhamento de informações, os Fab Labs e o movimento maker estão suscetíveis a associarem-se a concepções individualizantes e suprimirem o que há de possibilidade mínima para a construção coletiva na sociedade (FONSECA DE CAMPOS, 2018). Além disso, a informalidade dos mecanismos de trabalho, a exclusividade do conhecimento técnico e das práticas enquadram-se em condições sociais, culturais e econômicas muito específicas (NASCIMENTO; PÓLVORA, 2016), podendo desdobrar um contexto limitado dos Fab Labs e makerspaces em países periféricos.

O uso das novas tecnologias computacionais tornou-se tópico de interesse global, constituído segundo uma lógica em que investigações, experimentos e protótipos oriundos de países desenvolvidos, são divulgados e convertem-se em referências para pesquisas realizadas em outros países. Frente a esse contexto, muitas vezes centrado na divulgação técnica de propostas oriundas desses países, há certa escassez de trabalhos mais aprofundados sobre o assunto na América do Sul. Sendo assim, convém elucidar como as transformações oportunizadas pela disponibilidade de maquinário e técnicas são capazes de aperfeiçoar e contribuir para a criação de projetos, desenvolvimento de atividades e sistemas direcionados à esfera social e seus contextos de realização e seus propósitos. 0 problema se coloca de duas formas: a) compreender a situação local dos laboratórios que exploram as tecnologias; b) fornecer subsídios a partir do contexto da América do Sul para um pensamento crítico em relação à apropriação situada das técnicas e tecnologias.

0 artigo apresenta uma sistematização que torna visível uma perspectiva acerca da aplicação das tecnologias de fabricação digital em arquitetura, design e construção na América do Sul. A análise realizada referencia-se nos conceitos de apropriação tecnológica (BONSIEPE, 1983), adequação sociotécnica (DAGNINO, 2009) e inovação social (MANZINI, 2015). 0 primeiro, se refere à compreensão das tecnologias existentes, seus potenciais e limitações, a real necessidade de sua aquisição e futuras aplicações; o segundo, reflete sobre a conformidade de 
métodos e estratégias de ensino, serviço e produção em seu meio de inserção, às necessidades e aos atores envolvidos, a partir de conhecimentos prévios e sua capacidade de aprimoramento, utilizando as tecnologias como suporte em seus distintos níveis; o terceiro, foca na geração de projetos alternativos, e sua capacidade de modificar e redirecionar agendas de processos e de produção que impactem diretamente no bem-estar de uma comunidade.

Enquanto a esfera de aplicação da fabricação digital oriunda de países econômica e tecnologicamente desenvolvidos está devidamente registrada na literatura, são escassas as publicações que sistematizam projetos advindos de laboratórios na América do Sul. Portanto, a intenção de articular uma análise nesse sentido segue a compreensão de Mignolo (2003), a partir da qual "as histórias locais estão assumindo o primeiro plano e, da mesma forma, revelando as histórias locais das quais emergem os projetos globais com seu ímpeto universal" (p. 46), explicitando não somente algumas relações de poder manifestas nessa condição, mas também a oportunidade de considerar o outro lado da história enquanto liberação de um horizonte cultural (MIGNOLO, 2018).

O objetivo do artigo é elencar alguns experimentos projetuais identificados durante a pesquisa, para apresentar um panorama de produção recente na região, com base na aplicação das tecnologias de fabricação digital para a arquitetura, design e construção. De maneira específica: a) apresenta informações gerais sobre a situação e os modos de conformação dos laboratórios; b) identifica e organiza artefatos a partir de características comuns emergentes, baseadas nas noções de apropriação tecnológica, adequação sociotécnica e inovação social, representando especificidades emergentes de cada região; c) analisa a conjuntura geral em que emergem estas experiências, abrangendo alguns dos fatores tecnológicos, técnicos e sociais vinculados à fabricação digital em nossa região.

A investigação exploratória acerca dos laboratórios de fabricação digital na América do Sul, que dá suporte à pesquisa da qual este artigo apresenta um recorte, foi conduzida a partir de: a) revisão da literatura global e de publicações locais, foca das no tema da fabricação digital; b) mapeamento (ABRAMS; HALL, 2006) dos laboratórios de fabricação digitais com atividades vinculadas à arquitetura, design e construção na América do Sul, constituídos desde o início dos anos 2000; c) questionário (LUNE; BERG, 2017) aplicado para compreender informações institucionais, de infraestrutura, os usos das tecnologias e identidade da produção; d) estudos de caso (WANG; GROAT, 2015) baseados em projetos e protótipos resultantes de atividades didáticas, de pesquisa, oficinas, instalações artísticas e objetos de design, demandas para soluções de problemas e suportes para atividades práticas, organizados por meio de uma categorização.

Mais especificamente, o artigo apresenta informações parciais da pesquisa "Laboratórios de fabricação digital na América do Sul: estratégias, processos e artefatos para arquitetura e design", sendo derivado do trabalho intitulado "Technological appropriation and sociotechnical adequacy in South America: applications of digital fabrication in architecture and design", apresentado no XXII Congresso da Sociedade Iberoamericana de Gráfica Digital (SIGraDi) (SCHEEREN; SPERLING, 2018).:

\section{A DIFUSÃO DOS PARADIGMAS COMPUTACIONAIS E DA FABRICAÇÃO DIGITAL}

O paradigma computacional, relacionado aos processos de projeto e à produção da arquitetura, evoluiu nas últimas décadas devido ao seu uso como ferramenta de assistência ao desenho e para interfaces generativas, de construção da informação e de criação de formas complexas. Tal avanço contribuiu para que o arquiteto não estivesse atrelado às limitações técnicas e de logística do setor de produção industrial seriada, podendo controlar e customizar os resultados materiais utilizando tecnologias de fabricação digital. Uma das origens desse processo de desenvolvimento remonta ao período entre 1940 e 1950, quando foi criada e testada a 
primeira máquina de fresagem de controle numérico (CNC), em 1952, nos laboratórios de pesquisa de servomecânicos no MIT (Massachusetts Institute of Technology). Tal fato demonstra a convergência entre os interesses militares, da indústria e da academia, em "uma visão hegemônica da tecnologia que retratou de forma otimista os computadores como chave para o projeto nacional dos EUA de supremacia e competitividade global" (LLACH, 2015).

Não parece ser coincidência que na mesma instituição foi criado o modelo Fab Lab, uma proposta de espaço que inclui instruções para uso e aquisição de maquinário com um valor de até 50 mil dólares, que se concretizou no início dos anos 2000 por Neil Gershenfeld (2005), e logrou-se divulgar mundo afora. A vocação para criar tecnologias de automação em prol da indústria induziu o desenvolvimento de outras tecnologias de fabricação no mesmo país, a partir de meados dos anos 1980 e início dos anos de 1990, como a manufatura aditiva por meio de SLS, SLA e a FDM. Apesar da tecnologia FDM ter sido inventada naquele momento, é somente em meados e final da primeira década de 2000 que ela se difundiu, após o fim de patentes e mediante processos abertos compartilhados, como o projeto RepRap, e a comercialização de modelos de impressoras 3D desktop acessíveis e versáteis (CARPO, 2017, p. 75), como a MakerBot. Ao longo do tempo, algumas dessas tecnologias se desdobraram em técnicas avançadas para a construção, em parte, por meio da pesquisa experimental em universidades, com a ampliação de escala do maquinário e a diversidade de materiais empregados.

Além da divulgação do modelo de espaço de trabalho suportado pela cultura maker, rede e filosofia do Fab Lab MIT, outros fatores contribuíram para a crescente conformação de uma "cultura digital" de projeto e produção na área de arquitetura e design naquele período. Entre eles, o surgimento de interfaces de programação amigáveis aos usuários e tecnologias abertas de fácil compreensão; a publicação de projetos construídos e experimentos complexos que manifestavam integração das tecnologias digitais de outros setores em projeto, análise, fabricação e montagem (KOLAREVIC, 2005); as aspirações de design e os sistemas de fabricação digital que aproximaram a indústria manufatureira do setor da construção, instaurando novos vocabulários de projeto para arquitetura (SCHODEK et al., 2005); a utilização das máquinas para a prototipagem de objetos e modelos arquitetônicos em um processo integrado com o design digital, ensino e pesquisa em escolas de arquitetura, design e construção (SASS e OXMAN, 2006).

Os fatores mencionados acima difundiram-se globalmente e, em contextos como o da América do Sul, influenciaram claramente a formação de iniciativas de ensino, investigação e produção. Logo, é de fundamental relevância compreender como vem sendo realizadas apropriações e aplicações tecnológicas em cenários tão diversos na região, sendo que os resultados materializados por esses laboratórios são considerados aqui artefatos significativos para essa análise.

\section{PRECEDENTES DA PESQUISA E FUNDAMENTAÇÃO TEÓRICA PARA IDENTIFICAÇÃO E ANÁLISE DOS ARTEFATOS}

Em 2015, a exposição "Homo Faber: Digital Fabrication in Latin America" (SPERLING; HERRERA, 2015), na ocasião do congresso "CAAD Futures", reuniu de forma pioneira projetos desenvolvidos com suporte da fabricação digital em diversos países do nosso continente. A partir da mesma base de dados, o artigo "Migratory Movements of Homo Faber: Mapping Fab Labs in Latin America" (SPERLING, et al., 2015b) apresentou um mapeamento de informações, baseado em uma amostragem de laboratórios de fabricação instalados, nas redes de formação de conhecimento estabelecidas na América Latina e nas conexões com países de outros continentes. No ano seguinte, o projeto de pesquisa "Laboratórios de fabricação digital na América do Sul: estratégias, processos e artefatos para arquitetura e design", desenvolvido no programa de pós-graduação do Instituto de Arquitetura e Urbanismo da USP, iniciou um 
mapeamento de laboratórios de fabricação digital na América do Sul ligados a arquitetura, design e construção em instituições de ensino públicas e privadas, além de iniciativas independentes e escritórios. Este projeto busca sistematizar e compreender a situação dos laboratórios, suas dinâmicas de assimilação e aplicação das tecnologias, estratégias de trabalho, produção acadêmica e de projetos, para que se fomentem redes e dinâmicas de associação entre laboratórios com interesses e projetos similares.

0 contexto recente da fabricação digital na América do Sul se constitui em diversos tipos de espaços privilegiados para atividades com sua devida infraestrutura. Estes espaços, entendidos genericamente como "laboratórios", segundo especificidades institucionais e objetivos, foram classificados como "laboratório de pesquisa", "Fab Lab" e "escritórios de design". Eles foram incluídos na pesquisa a partir de suas relações com a arquitetura e o design de produto e se as suas atividades e produção são minimamente originais e relevantes para o contexto do qual emergem. Um primeiro resultado do mapeamento foi obtido a partir do material para a exposição "Homo Faber", redes específicas como "Makery" e "FabLabs.io", complementado por informações de buscas em websites e redes, utilizando palavras-chave relacionadas à "fabricação digital", e pelos questionários aplicados.

0 princípio das atividades dos laboratórios na região pode ser sintetizado em alguns marcos temporais. Um período inicial de instalação e uso das tecnologias por meio de alguns grupos de pesquisa em instituições de ensino por volta de 2007 e, nos anos seguintes, o surgimento dos primeiros Fab Labs e escritórios empregando as tecnologias. Por volta de 2012, há um período de expansão dos laboratórios em instituições de ensino e empreendimentos privados, que se acelera por volta de 2016, mais centrados em novos Fab Labs e escritórios de design aplicando as tecnologias de fabricação. É importante salientar que alguns desses laboratórios tiveram suas atividades descontinuadas durante o período do levantamento, um dado que revela questões de ordem econômica e de políticas de inovação na região. Em 2018, na ocasião do XXII Congresso da Sociedade Iberoamericana de Gráfica Digital (SIGraDi) intitulado "Tecnopolíticas", a exposição "Homo Faber 2.0: Politics of Digital in Latin America" (SCHEEREN; HERRERA; SPERLING, 2018) apresentou projetos realizados na América Latina que utilizam a fabricação digital para desenvolver processos e materializar artefatos que impactam positivamente nas relações entre produção e comunidades do contexto no qual se inserem.

Em artigo publicado anteriormente (SPERLING, et al., 2015a), a implementação dos laboratórios de fabricação digital em nosso contexto foi analisada sob os aspectos econômicos, acadêmicos e culturais. Em consonância com reflexões desenvolvidas na segunda exposição Homo Faber, esse artigo amplia a análise para compreender aspectos complementares aos já estabelecidos, no caso, o social e o político. No estágio em que se encontram, o aspecto econômico envolve a diminuição dos valores para compra e manutenção de maquinário, além de financiamentos de projetos por fomento público ou privado; o aspecto acadêmico manifesta o estabelecimento de grupos de pesquisa e atividades de ensino em instituições com a disseminação de conhecimento em publicações e em redes de compartilhamento técnico; o aspecto cultural ainda espelha referências produzidas em contextos distantes, mas indica diversidade na produção com especificidades temáticas, técnicas e materiais locais, além da adaptação de um movimento faça-você-mesmo por meio do compartilhamento de informações online, iniciativas em rede e sistemas distribuídos, como em oficinas e residências nos Fab Labs. 
Figura 1. Mapa dos laboratórios identificados com potencial para a pesquisa

Fonte: Autores, 2019

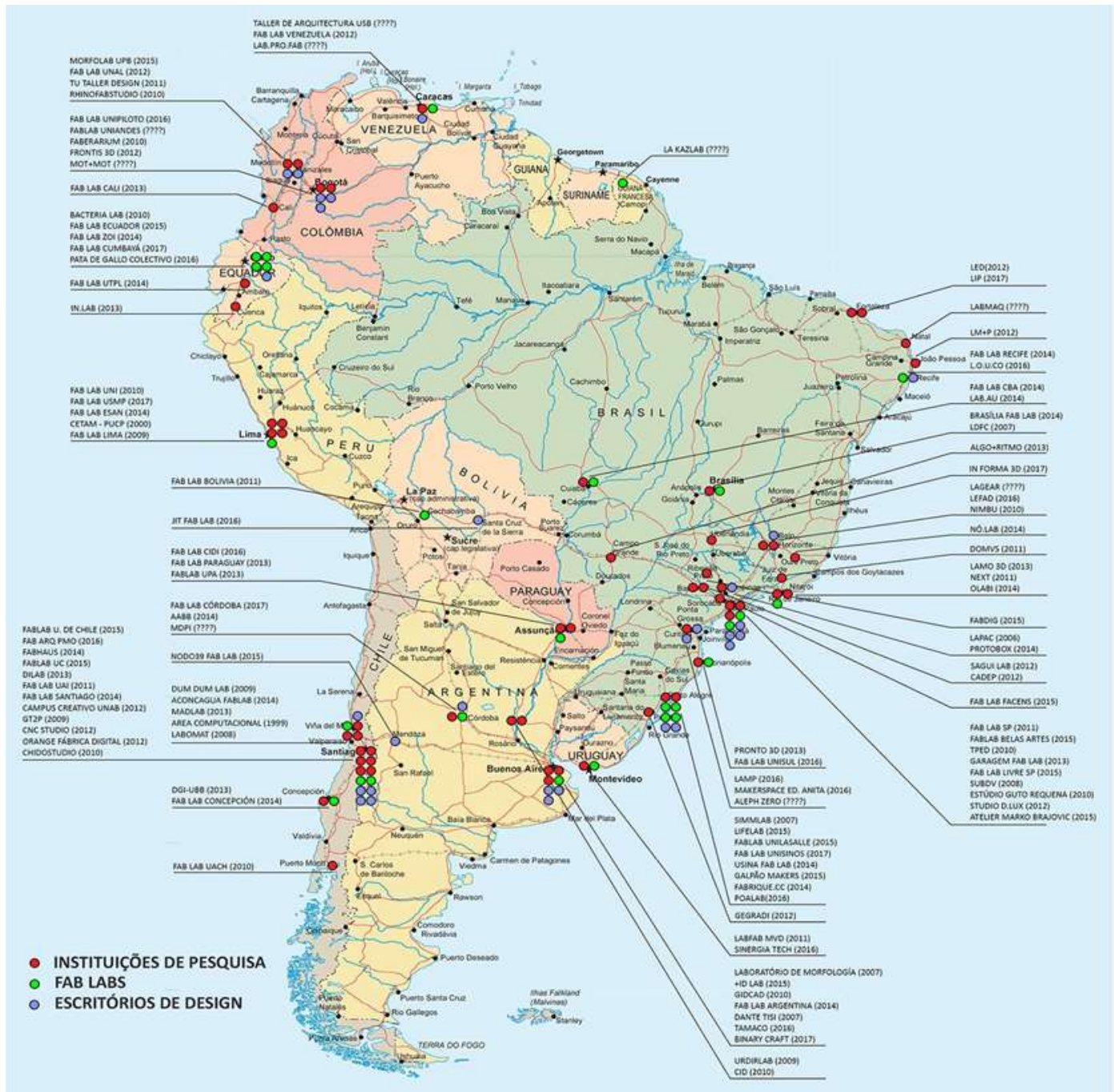

O aspecto social e político (LOMBARDERO \& DE CANALES, 2016) permeia os anteriores, ao incitar a reflexão sobre como os processos de projeto e produção com as novas tecnologias geram uma estrutura de mediação que representa os sujeitos envolvidos nesses processos, através da expressão material e formal. Procura-se compreender como as relações e ações no campo comum da sociedade podem ser promovidas com potencial de emancipação e transformação, gerando significado ao que é produzido, assim como verificar as atividades que permeiam a aplicação das tecnologias de fabricação digital. De modo mais específico, interessa compreender se e como a assimilação dessas tecnologias beneficia a produção relacionada às condições específicas de cada região, representa fatores culturais, influencia na resolução de problemas e contribui na dimensão do comum, com novas formas de trabalho e de participação.

A percepção desses acontecimentos parte da análise fundamentada em determinados temas apontados a seguir. Bonsiepe (1983) indicou a importância de abordar o tema da apropriação tecnológica, para compreender que sem a sua produção local por setores capacitados, é gerada uma condição de assimetria e dependência entre países periféricos e centrais. Ao não se estabelecer conjuntura favorável à inovação em cada sociedade, a tecnologia torna-se mercadoria que limita o processo de transferência crítica e de desenvolvimento econômico nesse campo. Desse modo, surge um desequilíbrio no qual a tecnologia torna-se instrumento de dominação que restringe a autonomia produtiva. 
Dagnino (2009) discute aspectos similares por meio do tema da adequação sociotécnica, segundo a qual o dispositivo tecnológico é apropriado e adaptado aos interesses políticos de grupos sociais relevantes, evitando "a ideia de que se possa simplesmente transferir tecnologias pré-concebidas" (DAGNINO, 2009, p. 63). Em vez de copiar saberes e técnicas, a ideia de "reaplicação" é colocada, quando o conhecimento e a tecnologia existentes são ajustados às particularidades de cada contexto, em que a noção de tecnologia se estabelece como resultado da ação de um ator social e decisão do coletivo. Além disso, a utilização dos recursos deve ser direcionada com o objetivo de maximizar o bem-estar da sociedade e do meio ambiente.

Por sua vez, Manzini (2015), sugere que a inovação social resulta de soluções desassociadas de modelos instituídos. Nesse sentido, o significado inerente às ações partiria de múltiplas expectativas e motivações dos atores envolvidos. Para que esse compartilhamento aconteça, é importante adaptar o conhecimento técnico, os materiais a disposição e integrar os atores com diferentes níveis de experiência em busca de novas soluções que extrapolem os modelos econômicos tradicionais, operando com base na multiplicidade de motivações e expectativas dos atores. Desse modo, "quanto mais pessoas forem expostas a essas tecnologias, maiores serão suas oportunidades e capacidade de absorvê-las, e entenderão como elas podem ser usadas ou adaptadas" (MANZINI, 2015, p. 16).

\section{IDENTIFICAÇÃO E ANÁLISE DOS ARTEFATOS: UMA AMOSTRAGEM INICIAL}

As aplicações da fabricação digital na arquitetura, design e construção, apresentam-se de maneira heterogênea entre os diversos laboratórios, evidenciando uma diversidade regional em seus resultados. Para o presente artigo, parte dos trabalhos de laboratórios expostos no mapa da Figura 1 foi selecionada segundo características específicas e aspectos comuns, que emergiram em relação à amostra geral, com foco nos temas apresentados anteriormente. Elencamos projetos realizados na Argentina - Nodo39 FabLab, TaMaCo e +ID Lab (Universidad de Buenos Aires)-, no Brasil - Fab Lab SP, Estúdio Guto Requena, LAMO 3D (Universidade Federal do Rio de Janeiro), LEAUD (Universidade Federal de Juiz de Fora) e LM+P (Universidade Federal da Paraíba) -, no Chile - Aconcagua FabLab (Pontificia Universidad Católica de Valparaíso), gt2P e FabHaus (Pontificia Universidad Católica de Chile) -, na Colômbia - Tu Taller Design, FabLab Unipiloto, MorfoLab (Universidad Pontificia Bolivariana) e Frontis 3d -, no Equador - FabLab UTPL -, no Peru - Fab Lab UNI -, e no Paraguai - FabLab Universitario CIDI (Universidad Nacional de Asunción). Os conjuntos apresentados foram elaborados a partir das similaridades das propostas e aplicações das tecnologias, complementados por breves análises relativas aos projetos neles inseridos.

1) "Abrigos experimentais" inclui estruturas espacializadas para proteção, investigação de suportes formais e materiais para a escala humana, além de módulos de habitação em seus diversos níveis de complexidade. Os projetos se baseiam em iniciativas semelhantes, como a wikihouse e os pavilhões. Em sua composição, empregam técnicas de corte e montagem a partir de peças regulares, elementos regrados ou curvilíneos, determinando padrões customizados e adaptáveis por meio de dobras e encaixes. As investigações formais têm o desafio de lidar com limitações materiais, adaptações às demandas funcionais, ambientais e às técnicas construtivas disponíveis. 


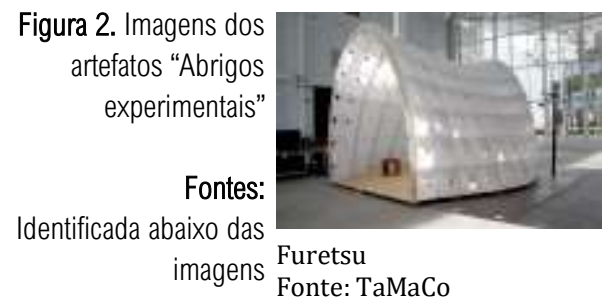

$\begin{aligned} & \text { Figura 2. Imagens dos } \\ & \text { artefatos "Abrigos } \\ & \text { experimentais" }\end{aligned}$
Fontes:
Identificada abaixo das
imagens
Furetsu
Fonte: TaMaCo

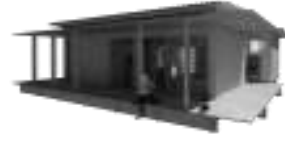

Casa Nordeste

Fonte: Carlos Alejandro Nome

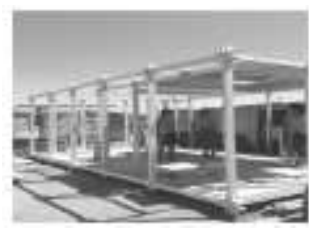

Nudo \#

Fonte: Tomás Vivanco,

Diego Gajardo

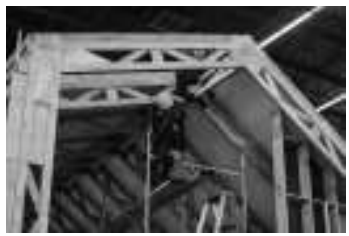

Casa Abierta

Fonte: David Del Valle

O pavilhão Furetsu (TaMaCo) foi criado pelo estúdio Formosa Design, em 2017, como instalação para um evento itinerante na Argentina. É composto de um esqueleto estrutural em madeira, com peças cortadas em fresadora CNC, encaixadas para formar um elemento de dupla curvatura suportando peças de plástico translúcido, cortadas a laser, dobradas e encaixadas em módulos customizados. 0 projeto da Casa Nordeste ( $\mathrm{LM}+\mathrm{P})$ investiga estratégias digitais para construir uma residência de baixo custo que contemple a eficiência de conforto e desempenho térmico para a região, além do uso de materiais e produtos sustentáveis. Utiliza a fabricação digital para o corte das peças da estrutura de compensado naval, junções estruturais e princípios de montagem. A técnica Nudo \# (FabHaus UC) é um sistema de construção baseado em uma peça de junção que permite a montagem de módulos habitáveis mínimos com a capacidade de serem expandidos. As peças de encaixe cortadas com fresadora CNC permitem facilmente que a estrutura possa ser montada, desmontada e transportada com facilidade. A Casa Abierta (Tu Taller Design) foi criada como um protótipo experimental para a Feira de Design de Medellín, como um resultado mais robusto e customizável para o mercado. 0 projeto é uma proposta sustentável composta de sistema modular de treliças laminares e chapas de madeira cortadas com fresadora CNC para serem pré-montadas.

2) "Infraestruturas e suportes" revisita concepções de sistemas e suportes materiais construtivos, facilitados em seu desenvolvimento e fabricação por ferramentas digitais. Os projetos envolvem elementos para espaços urbanos ou para a construção, em suas diferentes escalas e funções, seja como protótipos e testes funcionais ou para futuras aplicações em projetos. Os artefatos resultantes empregam técnicas industriais que podem ser aplicados em maior escala, com o intuito de se adaptarem às futuras demandas locais em projetos similares, suprirem problemas específicos ou se consolidarem como componentes duradouros.

Figura 3. Imagens dos artefatos "Infraestruturas e suportes"

Fontes: Identificada abaixo das imagens

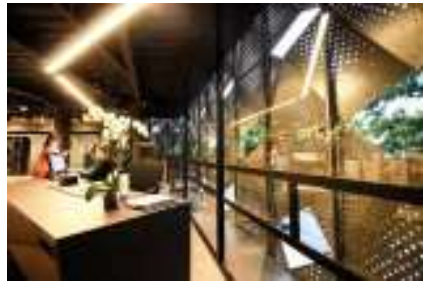

Fachada metálica dobrada Fonte: Rodrigo Velasco

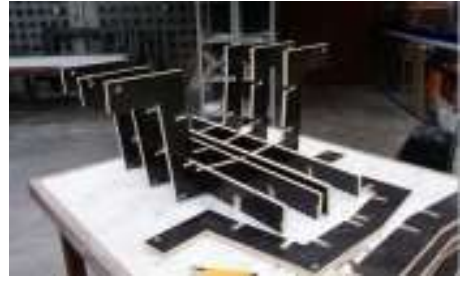

Forma para calçada drenante Fonte: Paulo Eduardo Fonseca de Campos

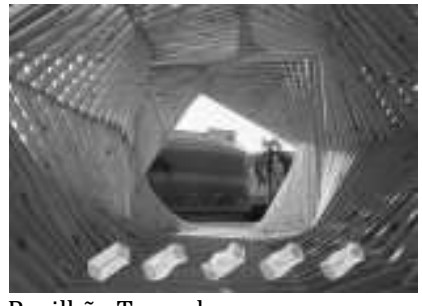

Pavilhão Tornado

Fonte: Gonçalo Castro Henriques

A fachada metálica dobrada (Frontis 3d) é um sistema customizado de painéis perfurados que tem a função de proteção e se adapta aos condicionantes da edificação como iluminação, ventilação e vista para o exterior. A fabricação utiliza capacidade ociosa da indústria local e que associa técnicas de suportes metálicos já aplicadas em outros projetos construtivos. A forma para calçada drenante (Fab Lab SP) é utilizada como molde feito de peças de compensado naval cortadas com fresadora CNC. As peças são encaixadas para formar canaletas pré-fabricadas em microconcreto de alto desempenho. Em conjunto, compõem uma galeria subterrânea de canalização pluvial para aprimoramento da infraestrutura urbana. O Pavilhão Tornado (LAMO 
3D) surgiu de uma atividade didática em que foi concebida uma intervenção temporária no espaço público, gerando espaço de permanência e descanso. O projeto é composto de superfícies regradas geradas digitalmente e construídas a partir de peças de madeira serradas, com demarcações de encaixe efetuadas com cortadora a laser.

3) "Materialidades artificiais" engloba experimentos que convergem formas e o comportamento dos materiais bioinspirados no âmbito da pesquisa básica, incorporando o aporte simbólico e conceitual no decorrer do seu processo. Os objetos são desenvolvidos por ressignificações do conceito de natureza e se utilizam de substâncias orgânicas; adequando o material ao ambiente no qual estão vinculados. Os elementos resultantes potencializam a criação de superfícies e recobrimentos adaptáveis às mais diversas estruturas e geometrias.

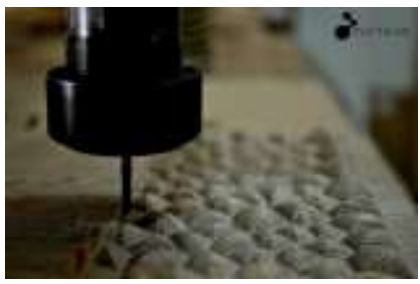

Superfícies bio-inspiradas Fonte: David Andrés Torreblanca Díaz

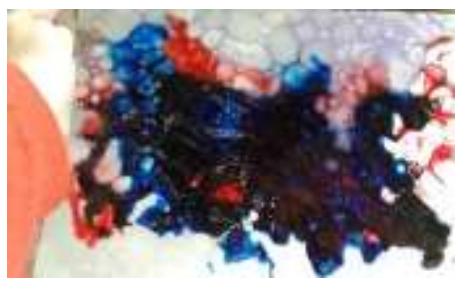

Tecnologías Expresivas - bioplástico Fonte: Gabriela Gonzales Faria

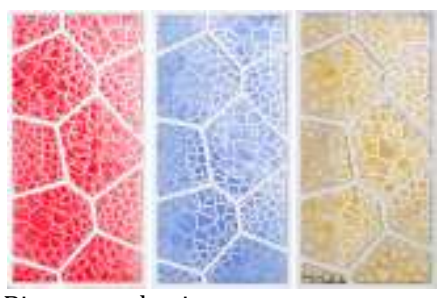

Bio-termoplastic Fonte: Pablo Suing
Figura 4. Imagens dos artefatos "Materialidades artificiais"

Fontes:

Identificada abaixo das imagens

As Superfícies Bio-inspiradas (Morfolab) resultam do propósito de unir superfícies e texturas em investigações com padrões inspirados nas espécies vegetais da região. A partir da modelagem digital, são criados elementos adaptativos com fresadora CNC e manufatura aditiva, que podem ter distintas aplicações no design de produtos. As Tecnologías Expresivas - bioplástico (FabLab Unipiloto) compõem experimentos materiais desenvolvidos por meio de atividade de ensino que utilizam a modelagem de resinas biodegradáveis com a finalidade de criar formas adaptáveis e irregulares, além de possibilitar que esse tipo de material possa ser testado com aplicação de manufatura aditiva. O Bio-termoplastic (FabLab UTPL) é um elemento de proteção para fachadas que filtra a alta intensidade da radiação UV na região equatoriana. A geometria complexa de voronoi foi gerada a partir de modelo digital, composta por resina e acrílico termocrômico, que resulta em uma estrutura rígida materializada com manufatura aditiva.

4) "Objetos informados" explora elementos formais e simbólicos que, por meio de suas partes simples, compõem artefatos complexos e articulados. As propostas partem de matrizes, módulos ou morfologias, que podem compor generativamente instalações e estruturas distintas do material originário por meio de informação digital ou intervenção humana. Resultam em composições interativas e com efeito lúdico, utilizando técnicas de impressão, corte de peças planas e montagem.

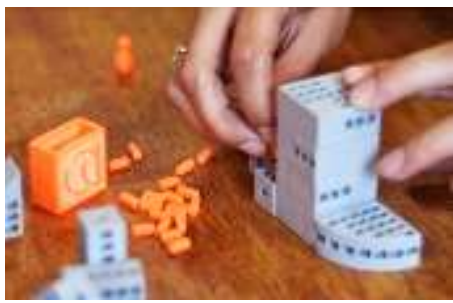

Jogo de montar ArchBricks Fonte: Frederico Braida

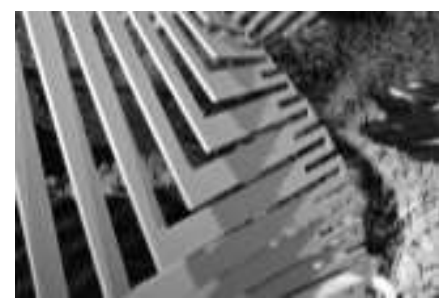

ALADA

Fonte: Rodrigo Martn Iglesias

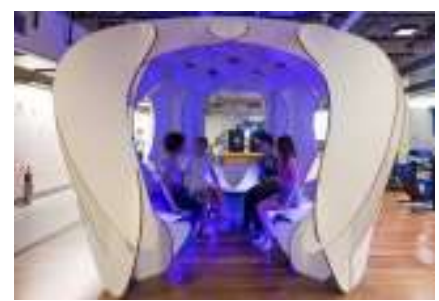

Empatias mapeadas Fonte: Guto Requena
Figura 5. Imagens dos artefatos "Objetos informados"

Fontes:

Identificada abaixo das imagens 
O jogo de montar ArchBricks (LEAUD) reúne componentes utilizados como um kit didático de ferramentas em que é possível montar simulações em escala reduzida de conjuntos habitacionais. A proposta parte de um projeto aberto em que as peças podem ser materializadas e adaptadas por manufatura aditiva. O ALADA (+ID Lab) é um objeto criado em colaboração com o Laboratório de Morfologia (FADU-UBA) e TaMaCo. A experimentação investiga relações entre a forma, o material e comportamento estrutural, além de explorar efeitos tridimensionais e simbólicos com o uso de elementos planos para um resultado estrutural. Empatias mapeadas (Estúdio Guto Requena) é uma instalação que oferece um espaço no formato de câmara para descanso e contemplação, informada por sensores que controlam efeitos de som e luz. As grandes peças de madeira, cortadas por fresadora CNC e encaixadas, abrigam um sistema interativo que envolve de maneira sensória os usuários.

5) "Artesanias híbridas" configura artefatos e instalações que auxiliam e otimizam a realização de atividades manuais, aproximando sistemas analógicos de processos de fabricação digital. Os projetos associam a revisão de técnicas artesanais desenvolvidas em cada região, considerando-as herança cultural que é incorporada como tema do artefato. Os objetos resultantes são compostos de materiais simples e procedimentos de montagem que são potencializados por meio das tecnologias digitais.

Figura 6. Imagens dos artefatos "Artesanias híbridas"

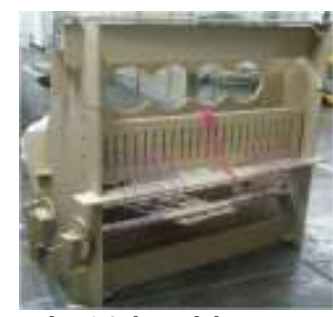

Telar 1.0 de pedal Fonte: Walter Gonzales Arnao

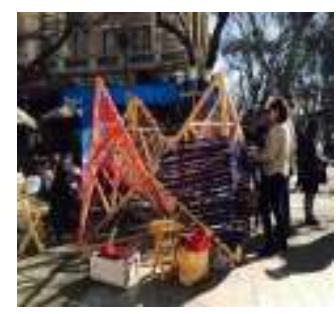

Estructura-bastidor de tejido

Fonte: Alicia Correa

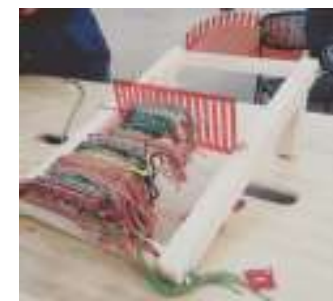

Dispositivo têxtil Fonte: Leo Aravena, Aconcagua Fablab

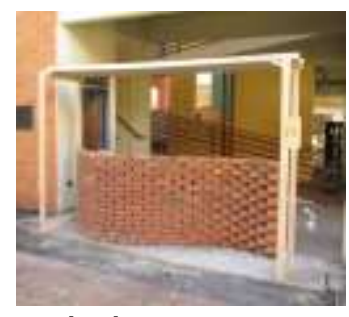

Parabrick

Fonte: Julio Diarte, FabLab Universitario CIDI

O Telar 1.0 de pedal (Fab Lab UNI) é um mecanismo portátil de alta performance que facilita processos de tecelagem para a composição de iconografias andinas. Composto por peças planas de madeira compensada, pode ser adaptado às necessidades manuais de diferentes tipos de pessoas e de trabalhos. A Estructura-bastidor de tejido (Nodo39 FabLab) é uma estrutura de madeira criada digitalmente para apoiar telas e pontos com a finalidade de constituir um tear de tecido. A instalação temporária foi criada para apresentar e conservar técnicas têxteis antigas dos indígenas da região central da Argentina, em um evento da indústria criativa de Mendoza. O Dispositivo têxtil (Aconcagua FabLab) é um artefato que reproduz um pequeno tear, facilitando a criação de pequenas peças têxteis, levado ao público a partir da proposta itinerante do laboratório. Composto de peças de madeira e acrílico cortadas a laser, a fabricação do objeto tem o objetivo de renovar o interesse pelas técnicas têxteis da região. O Parabrick (FabLab Universitario CIDI) é um dispositivo que fornece suporte para linhas-guia que funcionam para orientação de diversas composições geométricas de alvenaria. Fabricado digitalmente com peças de madeira fresadas e encaixadas, a estrutura pode ser montada no canteiro de obra e assim facilitar o trabalho manual.

6) "Dispositivos recodificados" abrange produções materiais relacionadas à reflexão conceitual acerca das tecnologias e suas aplicações práticas, criando novas dinâmicas de utilização. Os artefatos traduzem a subversão ou modificação do aparelho capaz de informar ou fabricar outros objetos. As máquinas de fabricação digital são designadas como base para reformulação e utilizadas para facilitar o processo de materialização por meio de técnicas de programação e montagem analógica ou eletrônica, com aplicações direcionadas a elementos plásticos e na geração de protótipos customizados. 


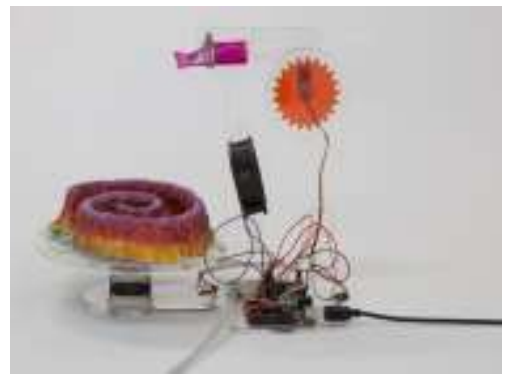

Digital Analogue Machines - Candelaria Fonte: Tomás Vivanco

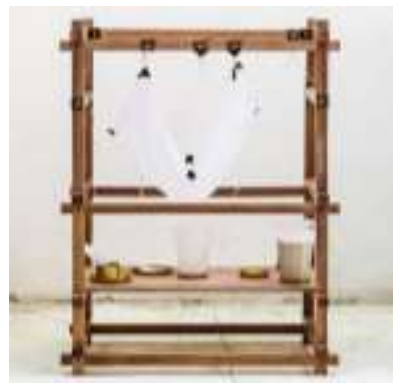

Less $\mathrm{N}^{\circ} 1$ Catenary Pottery Printer Fonte: Gt2P
Figura 7. Imagens dos artefatos "Dispositivos recodificados"

Fontes:

Identificada abaixo das imagens

O Digital Analogue Machines (FabHaus) é uma série de maquinações criadas por meio de atividades de ensino que reutilizam partes de dispositivos eletrônicos descartados. 0 intuito é criar objetos conceituais que associam manufatura personalizada, processos que se encontram entre o maquínico e o automatizado. 0 Less $\mathrm{N}^{\circ} 1$ Catenary Pottery Printer (gt2P) é uma máquina analógica que funciona por meio de uma estrutura fixa com elementos ajustáveis. Utilizando parâmetros controlados manualmente e o comportamento dos materiais, gera objetos cerâmicos não-estandardizados que ressignificam técnicas artesanais no contexto digital.

\begin{tabular}{|c|c|c|c|c|c|}
\hline & Projeto & Aplicação & Técnica & Tecnologia & Conceitos associados \\
\hline \multirow[t]{4}{*}{1} & Furetsu & Estande itinerante & Encaixe, dobra & $\begin{array}{l}\text { Fresadora, Corte } \\
\text { Laser }\end{array}$ & Adequação sociotécnica \\
\hline & Casa Nordeste & Construção resiliente & Encaixe & Fresadora & Inovação social \\
\hline & Nudo \# & Construção baixo custo & Encaixe & Fresadora & Inovação social \\
\hline & Casa Abierta & Habitação modulada & Encaixe, pregado & Fresadora & Adequação sociotécnica \\
\hline \multirow[t]{3}{*}{2} & Fachada metálica & Estrutura de proteção & Dobra, perfuração & $\begin{array}{l}\text { Fresadora, Corte } \\
\text { Laser }\end{array}$ & Apropriação tecnológica \\
\hline & $\begin{array}{l}\text { Forma para } \\
\text { calçada }\end{array}$ & Molde para saneamento & Encaixe, colagem & Fresadora & Inovação social \\
\hline & Pavilhão Tornado & $\begin{array}{l}\text { Estrutura em espaço } \\
\text { público }\end{array}$ & Encaixe & Corte Laser & Adequação sociotécnica \\
\hline \multirow[t]{3}{*}{3} & $\begin{array}{l}\text { Superfícies bio- } \\
\text { inspiradas }\end{array}$ & Elementos morfológicos & Desbaste, adição & $\begin{array}{l}\text { Fresadora, } \\
\text { Impressão 3d }\end{array}$ & Adequação sociotécnica \\
\hline & $\begin{array}{l}\text { Tecnol. Expres. } \\
\text { bioplástico }\end{array}$ & Material de proteção & Moldagem & Formativa & Adequação sociotécnica \\
\hline & Bio-termoplastic & Componente de proteção & Moldagem & Formativa & Inovação social \\
\hline \multirow[t]{3}{*}{4} & Jogo ArchBricks & Objeto lúdico/didático & Adição, encaixe & Impressão 3d & Adequação sociotécnica \\
\hline & ALADA & $\begin{array}{l}\text { Instalação } \\
\text { técnico/simbólica }\end{array}$ & Corte em padrões & Corte Laser & Apropriação tecnológica \\
\hline & $\begin{array}{l}\text { Empatias } \\
\text { mapeadas }\end{array}$ & Instalação sensorial & Encaixe & Fresadora & Apropriação tecnológica \\
\hline \multirow[t]{4}{*}{5} & Telar 1.0 de pedal & Aparelho para tecelagem & Encaixe & Corte Laser & Apropriação tecnológica \\
\hline & $\begin{array}{l}\text { Estructura- } \\
\text { bastidor }\end{array}$ & $\begin{array}{l}\text { Instalação para manuseio } \\
\text { técnico têxtil }\end{array}$ & Encaixe & Corte Laser & Adequação sociotécnica \\
\hline & Dispositivo têxtil & $\begin{array}{l}\text { Aparelho portátil para } \\
\text { tecelagem }\end{array}$ & Encaixe & Corte Laser & Apropriação tecnológica \\
\hline & Parabrick & Aparato para canteiro & Encaixe & Corte Laser & Adequação sociotécnica \\
\hline \multirow[t]{2}{*}{6} & $\begin{array}{l}\text { Digital Analogue } \\
\text { Machines }\end{array}$ & $\begin{array}{l}\text { Máquina geradora de } \\
\text { elemento artístico }\end{array}$ & Montagem & $\begin{array}{l}\text { Corte Laser, } \\
\text { Impressão 3d }\end{array}$ & Apropriação tecnológica \\
\hline & Less $\mathrm{N}^{\circ} 1$ Catenary & $\begin{array}{l}\text { Mecanismo artesanal de } \\
\text { controle manual }\end{array}$ & Montagem & $\begin{array}{l}\text { Corte Laser, } \\
\text { Impressão 3d }\end{array}$ & Adequação sociotécnica \\
\hline
\end{tabular}

Tabela 1. Síntese da identificação dos projetos

Fontes:

Autores

\section{DISCUSSÃO DOS RESULTADOS}

Os projetos apresentados caracterizam uma amostra oportuna para demarcar o que está surgindo nos distintos contextos de nossa região, em termos de técnicas de produção, práticas situadas, aplicações das tecnologias e adequações sociais. A produção dos laboratórios, de 
maneira geral, ainda está mais direcionada à aplicação das tecnologias para a fabricação de protótipos e modelos arquitetônicos, peças de mobiliário e objetos de design. A escala dos projetos limita-se a objetos pequenos e medianos, com poucas articulações na escala da construção. As distintas dinâmicas de funcionamento dos laboratórios influenciam nos modos de concepção e de fazer dos artefatos, em que alguns encontram-se em espaços privados e direcionam a sua produção ao mercado e às exposições de design, outros criam estratégias colaborativas a partir de demandas de parcerias externas. Os tipos de espaços disponibilizados pelos laboratórios, são abertos à participação, com propostas de residências, oficinas e instalações, além dos institucionais, regulados pelo ensino, pesquisa e extensão, com o potencial de integração conjunta a diversos setores da sociedade. A configuração de boa parte dos laboratórios está baseada em organizações nucleadas, amparadas na proposta da rede global Fab Lab, dos quais alguns estão expandindo a sua atuação por meio de unidades móveis.

Os temas selecionados para a escolha dos projetos apresentados nesse artigo contribuem para delimitar um recorte dos resultados materiais encontrados durante a pesquisa. A articulação híbrida entre o analógico e o digital destaca-se em muitos projetos, devido à restrição dos materiais possíveis de serem utilizados no maquinário disponível e pelo domínio técnico necessário para fazê-lo. Ao mesmo tempo, torna-se um potencial para a criação de resultados formais e combinações materiais não-usuais. As técnicas mais utilizadas são o seccionamento para encaixe, seguido do uso de técnicas aditivas, além de técnicas de dobradura e montagem. Em termos formais, as geometrias retilíneas e planas são mais recorrentes, pois o acesso ao tipo de maquinário que as produz facilita o processo de fabricação e montagem em maior escala, Os materiais utilizados são rígidos mas com resistência limitada, como madeira, plástico e peças flexíveis, em que poucos artefatos incorporam elementos locais.

A escolha do maquinário vem seguindo critérios de custo, facilidade de manipulação e aprendizado, não baseada em necessidades urgentes de aplicação. Impressoras 3D e cortadoras a laser são preferidas a equipamentos robustos e industriais, pautados por tecnologias disponibilizadas por empresas internacionais, dos EUA, Europa e China. É possível encontrar máquinas sendo criadas em nossa região, com funções e aplicações específicas, mas poucas e em âmbito experimental. 0 uso de robôs na automação de processos de fabricação ainda é uma realidade distanciada, que está em estágio de assimilação técnica em poucas instituições. À medida que se amplia o controle tecnológico em nosso contexto de restrições aquisitivas, o domínio técnico passa a ser exigido do profissional em um nível de superespecialização, o que dificulta um salto no nível de fabricação.

Como alternativa, incorporam-se conceitos, saberes convencionais e práticas analógicas para um maior grau de liberdade propositiva e de inserção do potencial das interfaces digitais e das máquinas para se alcançar estratégias híbridas. Os projetos apresentados indicam diferentes níveis de impacto em termos de inovação social, com apenas alguns deles associando de forma mais explícita essa estratégia na concepção de projeto. Boa parte deles tangencia fatores de adequação sociotécnica ao adaptarem técnicas processuais, de controle da fabricação e de materiais para a produção. A apropriação tecnológica se explicita nos trabalhos ao utilizarem o maquinário como suporte parcial para a execução dos artefatos. Apesar dessas noções não estarem explicitamente difundidas, no contexto geral, percebe-se que o interesse de envolvimento com os temas se mostra crescente.

Baseado na análise dos projetos escolhidos, é possível designar especificidades e limitações do uso da fabricação digital em nosso contexto. A adaptação de referências técnicas e de projeto de um panorama global ocorre, geralmente, com baixo grau de complexidade propositiva. 0 enfrentamento da escassez e da limitação dos meios e materiais induz a criação de estratégias particulares para servir necessidades mais urgentes e respostas a requisições eventuais. A combinação de técnicas e materiais por meio de investigações formalizadas realizam-se, quase que exclusivamente em instituições de ensino. 0 potencial de revisão das práticas artesanais 
articula-se com a manutenção da identidade de comunidades, com o intuito de recuperar simbolismos, e também fomentar uma indústria criativa. A valorização de fatores ambientais comparece como condicionantes situados para a geração de artefatos funcionais. A participação de agentes com distintos saberes e experiências, externos aos laboratórios, acontece apenas de forma pontual em alguns projetos. A fabricação digital vem oferecendo ferramentas para explorar artefatos conceituais e artísticos.

Com a ausência de um panorama claro e amplamente discutido sobre as contribuições da fabricação digital em nosso contexto, a tendência, em um primeiro momento, foi de espelhamento de propostas do exterior, principalmente com o intuito de assimilação das técnicas digitais. A atribuição de sentido que conferiu envergadura à incorporação das tecnologias de fabricação digital na América do Sul derivou das possibilidades de inovação veiculadas em países desenvolvidos, mas ainda não verificadas em escala, seja de processos e produtos customizados que seriam de grande complexidade, ou com custo e tempo de produção reduzidos. Logo, percebe-se certa fetichização do potencial de uso das máquinas. Além desses aspectos, a formação de redes de conhecimento acontece de maneira cambiante, pouco abrangente e limitada a iniciativas em determinadas regiões. Outro fator que causa inconstâncias são as mudanças de políticas públicas e os recorrentes cortes em investimentos em pesquisa e desenvolvimento de tecnologias com base local.

\section{CONCLUSÃO}

A utilização das tecnologias de fabricação digital encontra espaço privilegiado em centros de ensino e investigação, makerspaces e, de forma secundária, em escritórios na América do Sul. Nesse sentido, o esforço em identificar e compreender a situação e a produção dos laboratórios fornece subsídios para se pensar aprimoramentos na sua aplicação, a expansão das atividades com as tecnologias digitais, além de conexões com outros profissionais e setores de produção. 0 estado da arte da fabricação digital na América do Sul evoluirá quase que necessariamente dependente de conexões em rede e por via de conhecimento multidisciplinar. De modo que os temas da apropriação tecnológica, adequação sociotécnica e inovação social possam ser, dentre outros similares, capazes de determinar sentido e o impacto dos projetos, situando-se como dispositivos críticos em relação às tecnologias, a fim de situá-las nas diversas condições sociais em que se instalam. A sistematização presente neste artigo serviu como ensaio em um esforço de categorização dos projetos, com desdobramentos em publicações futuras. 0 mapeamento, que já vinha sendo elaborado, pode ser complementado e ampliado futuramente, além de desdobrado em estudos de caso mais focados nas similaridades entre atividades, técnicas e tipos de artefatos. Com efeito, a partir desse material, será possível delinear teorias fundamentadas sobre o presente e o futuro das aplicações da fabricação digital em arquitetura, design e construção na América do Sul.

\section{Agradecimentos}

Este trabalho foi financiado pela Fundação de Amparo à Pesquisa do Estado de São Paulo (FAPESP), processo no 2017/04946-7 e pelo Conselho Nacional de Desenvolvimento Científico e Tecnológico (CNPq), processo no 304071/2019-6. 
Aplicações da fabricação digital em arquitetura, design e construção: processos de apropriação tecnológica e adequação sociotécnica em experimentos na América do Sul

\section{Referências Bibliográficas}

ABRAMS, Janet; HALL, Peter (Eds.). Else/where: mapping. New cartographies of networks and territories. Minneapolis: University of Minnesota, 2006.

BONSIEPE, Gui. A tecnologia da tecnologia. São Paulo: Edgard Blücher, 1983.

CANEPARO, Luca. Digital Fabrication in Architecture, Engineering and Construction. Dordrecht: Springer, 2014.

CARPO, Mario. The Second Digital Turn: Design Beyond Intelligence. Cambridge: MIT Press, 2017.

CELANI, Gabriela. Digital Fabrication Laboratories: Pedagogy and Impacts on Architectural Education. Nexus Network Journal, v. 14, 2012, 469-482. DOI: <http://dx.doi.org/10.1007/s00004-012-0120-x>

DAGNINO, Renato (Org.). Tecnologia social: ferramenta para construir outra sociedade. Campinas: IG/UNICAMP, 2009.

FONSECA DE CAMPOS, Paulo Eduardo; DIAS, Henrique José dos Santos. A insustentável neutralidade da tecnologia: o dilema do Movimento Maker e dos Fab Labs. Liinc em Revista, v.14, n.1, maio 2018, p. 33-46. DOI: <http://dx.doi.org/10.18617/liinc.v14i1.4152>.

GERSHENFELD, Neil. Fab: The Coming Revolution on Your Desktop - from Personal Computers to Personal Fabrication. Cambridge: Basic Books, 2005.

GERSHENFELD, Neil. How to make almost anything: the digital fabrication revolution. Foreign Affairs, V. 91, n. 43, nov./dez. 2012, p. 43-57.

KOLAREVIC, Branko. Architecture in the Digital Age: Design and Manufacturing. New York: Taylor \& Francis, 2005.

LLACH, Daniel Cardoso. Software Comes to Matter: Toward a Material History of Computational Design. Design Issues, V. 31, n.3, July 2015, p. 41-54. DOI: <http://dx.doi.org/10.1162/DESI_a_00337>.

LOMBARDERO, Nuria. Á., DE CANALES, Francisco. G. Política y Fabricación Digital: una discusión en curso. Sevilla: Vibok Works, 2016.

LUNE, Howard; BERG, Bruce L. Qualitative Research Methods for the Social Sciences. Essex: Pearson, 2017.

MANZINI, Ezio. Design when everybody designs: an introduction to design for social innovation. Cambridge: MIT Press, 2015.

MENGES, Achim; AHLQUIST, Sean (Ed.). Computational Design Thinking, (AD Reader). Chichester: Wiley, 2011.

MIGNOLO, Walter D.; WALSH, Catherine E. On decoloniality: concepts, analytics, praxis. Durham: Duke University Press, 2018.

MIGNOLO, Walter D. Histórias locais, projetos globais: colonialidade, saberes subalternos e pensamento liminar. Belo Horizonte: Editora UFMG, 2003.

NABONI, Roberto; PAOLETTI, Ingrid. Advanced Customization in architectural design and construction. Dordrecht: Springer, 2015.

NASCIMENTO, Susana; PÓLVORA, Alexandre. Maker Cultures and the Prospects for Technological Action. Science and Engineering Ethics, V. 24, n. 3, 2018, p. 927-946. 
PICON, Antoine. Digital culture in architecture: an introduction for the design profesions. Basel: Birkhäuser, 2010.

SASS, Larry; OXMAN, Rivka. Materializing design: the implications of rapid prototyping in digital design. Design Studies, n. 27, 2006, p. 325-355. DOI: 10.1016/j.destud.2005.11.009

SCHEEREN, Rodrigo; HERRERA, Pablo C.; SPERLING, David (eds). Homo Faber 2.0: politics of digital in Latin America. São Carlos: IAU/USP, 2018.

SCHEEREN, Rodrigo; SPERLING, David M. Technological appropriation and socio-technical adequacy in South America: applications of digital fabrication in architecture and design. Proceedings of the 21st Congress of the Iberoamerican Society of Digital Graphics, 2018. DOI: 10.5151/sigradi20181802.

SCHODEK, Daniel; BECHTHOLD, Martin; GRIGGS, James Kimo; KAO, Kenneth; STEINBERG, Marco. Digital Design and Manufacturing: CAD/CAM Applications in Architecture and Design. London: John Wiley \& Sons, 2005.

SPERLING, David M.; HERRERA, Pablo (eds). Homo Faber: Digital Fabrication in Latin America. São Carlos: Instituto de Arquitetura e Urbanismo USP, 2015.

SPERLING, David M.; HERRERA, Pablo; CELANI, Gabriela, SCHEEREN, Rodrigo. Fabricação digital na América do Sul: um mapeamento de linhas de ação a partir da arquitetura e urbanismo. Proceedings of the 19th Congress of the Iberoamerican Society of Digital Graphics. São Paulo: Blucher, 2015, p. 119-125. DOI: 10.5151/despro-sigradi2015-30212

SPERLING, David M.; HERRERA, Pablo; SCHEEREN, Rodrigo. Migratory Movements of Homo Faber: Mapping Fab Labs in Latin America. In.: Computer-Aided Architectural Design Futures. The Next City - New Technologies and the Future of the Built Environment: 16th International Conference, CAAD Futures 2015, São Paulo - Selected Papers. Heidelberg: Springer Verlag, 2015, p. 405-421. DOI: 10.1007/978-3-662-47386-3_22

WANG, David; GROAT, Linda. Architectural research methods (second edition). New Jersey: John Wiley and Sons, 2015. 